\title{
$\mathrm{OBP}$ 위성 시스템에서 보호 대역과 양자화 레벨이 $\mathrm{BER}$ 성능에 미치는 영향 분석
}

\author{
강기완*, 윤동원*
}

\section{Effect Analysis of Guard Band and Quantization Level on BER Performance in OBP Satellite Systems}

\author{
Kiwan Kang* and Dongweon Yoon*
}

\begin{abstract}
MCDD performs demultiplexing and demodulation of multi-carrier signals for signal processing schemes such as switching, channel encoding and remodulation in an OBP satellite. During the demultiplexing procedure, several factors such as frequency offset and/or quantization error degrade BER performance. Hence, influences of those factors should be reduced. A influence of the frequency offset can be reduced by inserting guard band between channels, and that of quantization error can be decreased by quantization level control. In case that the data rate of system is not limited, the guard band and the quantization level do not affect each other. In the other case, however, mutual influence between them should be considered. In this paper, we observe the mutual influence when the data rate of the MCDD is limited, and analyze the BER performance.
\end{abstract}

\section{초 록}

$\mathrm{MCDD}$ 는 다채널 신호를 수신 받아 분리하고 복조하여 $\mathrm{OBP}$ 위성의 내부에서 스위칭, 채널 부호화 및 재변조 등의 신호처리가 가능하도록 하고 있다. 다채널 신호를 분리하는 과정에서 주파수 오프셋 및 양자화 오류 등의 요인들이 OBP 위성 시스템의 BER 성능을 저하시키므로 이러한 요인들의 영향을 줄여야 한다. 주파수 오프셋의 영향은 보호 대역을 삽입함으로써 줄일 수 있으며 양자화 오류의 영향은 양자화 레벨을 조정함으로써 줄일 수 있다. 시스템의 데이터 전송률을 제한하지 않았을 때 보호 대역의 삽입과 양자화 레벨 의 조정은 서로 영향을 미치지 않으나, 시스템의 데이터 전송률이 제한되면 보호 대역의 삽입과 양자화 레벨의 조정을 상호 고려해야 한다. 이 논문에서는 시스템의 데이터 전송 률이 제한된 상황에서 보호 대역과 양자화 레벨간의 관계를 살펴보고 이를 고려한 BER 성능을 분석한다.

Key Words : MCDD, $\mathrm{OBP}$ (온보드프로세싱), Guard Band(보호 대역), Quantization Level(양자화 레벨)

\footnotetext{
† 2010년 2월 8일 접수 2010년 5월 26일 심사완료

* 정회원, 한양대학교 전자통신공학부 교신저자, E-mail : dwyoon@hanyang.ac.kr 서울특별시 성동구 행당1동
}

$$
\text { I. 서 론 }
$$

통신 기술의 발달과 기존 통신 시장의 포화는 통신 사업자들로 하여금 사용자들의 요구에 맞추 어 다양한 고속의 멀티미디어 서비스를 제공하도 
록 만들고 있다. 이를 위하여 통신 사업자들은 위성을 이용하는 멀티미디어 통신 및 네트워크를 구축하기 위한 연구를 활발히 진행 중에 있다[1] ,[2]. 해외의 위성 통신 선진국들은 다채널의 멀 티미디어 신호를 원하는 지역에 효율적으로 전송 하기 위해 OBP(On-Board Processing) 기술을 위 성에 탑재하여 스위칭, 채널 부호화, 신호의 복조 및 재변조 등의 다양한 신호처리 과정을 거치게 함으로써 수신 신호의 재생 및 재분배가 가능하 도록 하고 있다. $\mathrm{OBP}$ 위성의 $\mathrm{MCDD}(\mathrm{Multi}-$ Carrier Demultiplexer/Demodulator)는 지상국에 서 전송한 다채널 신호를 수신하여 각 채널별로 분리하고 복조하는 역할을 수행하는데, 신호를 분리하는 과정에서 주파수 오프셋 및 양자화 오 류 등의 요인들이 OBP 위성 시스템의 BER(Bit Error Rate) 성능을 저하시킨다[3],[4]. 그러므로 $\mathrm{OBP}$ 위성을 이용한 효율적인 통신 시스템을 설 계하기 위해서는 이러한 요인들에 의한 성능 열 화를 줄여야 한다. 주파수 오프셋의 영향은 보호 대역을 삽입하여 줄일 수 있으며 양자화 오류의 영향은 양자화 레벨을 조정하여 줄일 수 있다. 이 때, 보호 대역의 삽입은 신호의 주파수 대역 을 증가시키므로 디지털 신호로 변환할 경우 비 트 전송률의 증가를 야기하고 양자화 레벨은 디 지털 변환 과정에서 하나의 신호 샘플을 표현하 는 비트 수를 결정하므로 보호 대역의 삽입과 양 자화 레벨 값의 조정은 신호의 비트 전송률을 변 화시킬 수 있다. 시스템의 데이터 전송률이 제한 되지 않은 환경에서는 이론적으로 신호의 비트 전송률이 무한히 클 수 있기 때문에 보호 대역의 삽입과 양자화 레벨의 조정은 서로 영향을 미치 지 않으나 시스템의 데이터 전송률이 제한된 환 경에서는 신호의 비트 전송률이 시스템의 데이터 전송률을 초과할 수 없기 때문에 보호 대역의 삽 입과 양자화 레벨의 조정을 상호 고려해야 한다. 기존의 $\mathrm{MCDD}$ 의 성능을 분석하기 위한 논문들
은 성능에 영향을 주는 요소들만을 중점적으로 고려하였다[3],[4]. 그러나 실제 시스템에서는 $\mathrm{MCDD}$ 의 데이터 전송률을 무한히 크게 할 수 없다. 따라서 이 논문에서는, $\mathrm{MCDD}$ 시스템에 영향을 미치는 요소들에 대해 자세히 분석한 [4] 논문의 연장선으로, 기존 양자화 오류가 존재하 는 환경에서 양자화 레벨이 SNR(Signal to Noise Ratio)과 데이터 전송률에 미치는 영향에 대해 분석하고 주파수 오프셋이 존재하는 환경에서 보 호 대역이 SNR과 데이터 전송률에 미치는 영향 에 대해 분석한다. 또한, 시스템의 데이터 전송률 이 제한된 상황에서 보호 대역과 양자화 레벨간 의 상호 관계를 살펴보고 이를 DVB-S(Digital Video Broadcasing-Satellite) 시스템에 적용하여 $\mathrm{BER}$ 성능을 분석한다.

이 논문의 구성은 다음과 같다. 2.1장에서 양 자화 레벨이 수신 신호의 SNR과 신호의 비트 전 송률에 미치는 영향을 분석하고 2.2장에서 보호 대역이 수신 신호의 SNR과 신호의 대역폭에 미 치는 영향에 대해 분석한다. 2.3장에서 수신 신호 의 대역폭이 신호의 비트 전송률에 미치는 영향 에 근거하여 시스템의 데이터 전송률이 제한된 환경에서의 보호 대역과 양자화 레벨간의 관계를 살펴보고 이를 고려한 $\mathrm{BER}$ 성능을 분석한 후 3 장에서 결론을 맺는다.

\section{II. 본 론}

\section{1 양자화 레벨에 의한 영향 분석}

다채널 신호를 분리하기 위한 $\mathrm{MCDD}$ 는 Fig. 1 과 같이 $\mathrm{RF}$ (Radio Frequency) 주파수를 낮춰주 는 주파수 하향 변환기(Down Converter), 아날 로그 신호를 디지털 신호로 변환하기 위한 디지 털 변환기(A/D Converter: Analog to Digial

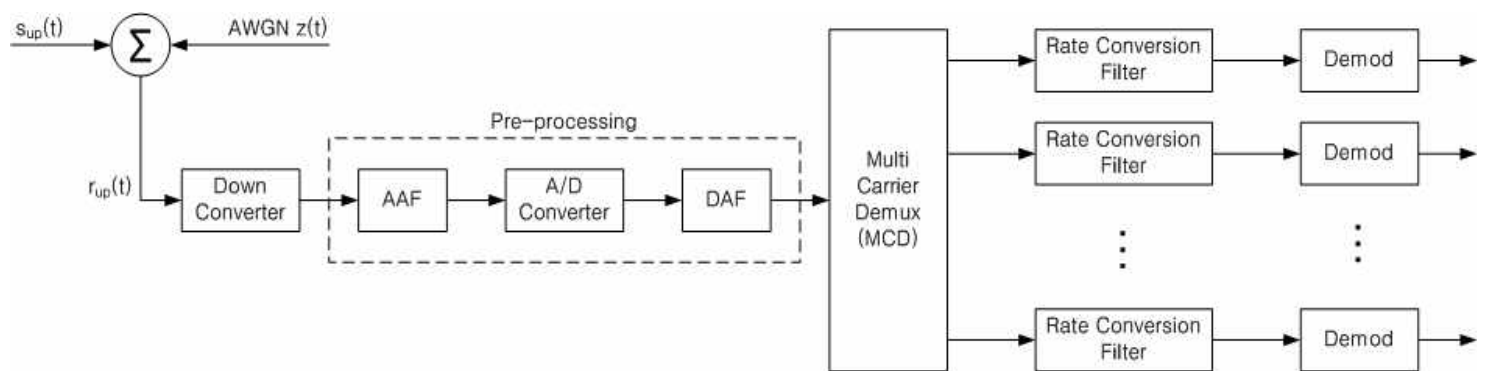

Fig. 1. Block diagram of $N$-channel MCDD 
Converter) 및 아날로그 앨리어싱 제거필터(AAF: Analog Anti-aliasing Filter)와 디지털 앨리어싱 제거필터(DAF: Digtal Anti-aliasing Filter)가 포 함된 전처리 과정, 각 채널의 신호를 분리하기 위한 $\mathrm{MCD}($ Multi-Carrier Demultiplexer), 신호의 비트 전송률을 바꾸는 전송률 변환 필터(Rate Conversion Filter) 그리고 신호를 복원하기 위한 복조기(Demod: Demodulator)로 구성된다. 지상 국에서 전송한 신호 $s_{u p}(t)$ 는 가산성 백색 가우 시안 잡음(AWGN: Additive White Gaussian Noise), $z(t)$ 와 함께 수신되며, 수신 신호 $r_{u p}(t)$ 는 디지털 변환기를 통해 디지털 신호로 변환된 다.

수신 신호의 대역폭을 $B_{\text {signal, }}$ 샘플링 주파수 $f_{s}=2 \beta B_{\text {signal, }}$ 그리고 양자화 레벨을 $M$ 이라고 하면, 디지털 변환기를 거친 수신 신호의 비트 전송률 $R_{\text {signal }}$ 은 다음과 같이 표현된다.

$$
R_{\text {signal }}=2 \beta B_{\text {signal }} \log _{2} M \quad[b p s]
$$

여기서 $\beta$ 는 오버 샘플링 값으로 나이키스트 (Nyquist) 이론에 의해 $\beta \geq 1$ 을 만족해야 한다.

실제로 $\mathrm{MCDD}$ 프로세서의 데이터 전송률 $R_{\text {system }}$ 은 무한할 수 없기 때문에 $\mathrm{MCDD}$ 시스템 에서 각 채널 신호들을 분리하고 복조할 때, 수 신 신호를 정확하게 분리하고 복조하기 위해 수 신 신호의 비트 전송률 $R_{\text {signal }}$ 은 $\mathrm{MCDD}$ 시스템 의 데이터 전송률 $R_{\text {system }}$ 보다 작거나 같아야 하 며 다음과 같은 식으로 표현된다.

$$
R_{\text {system }} \geq 2 \beta B_{\text {signal }} \log _{2} M[\text { bps }]
$$

수신 신호를 $M$ 의 양자화 레벨로 양자화 한 경우, $\mathrm{PPF}$ (Poly Phase FFT) 방식 $\mathrm{MCDD}$ 에 의해 서 분리된 $k$ 번째 채널 신호의 $\mathrm{SNR}, S N R_{k}$ 는 식 (3)과 같이 표현될 수 있다[4].

여기서 $N_{Q}^{A}=\left\{N_{Q}^{2}+N\left(N_{Q 2}^{H B F}+N_{Q 3}^{H B F}+\gamma^{2} S\right)\right\} / N$ 는 디지 털 변환기와 디지털 앨리어싱 제거 필터에 의한 양자화 오류; $N_{Q_{2}}^{H B F}=(C+1) \cdot 2^{-2 b} / 3$ 는 디지털 앨 리어싱 제거 필터 인수에 의한 양자화 오류; $N_{Q_{3}}^{H B F}=(C+1) \cdot 2^{-2 b} / 6$ 는 디지털 앨리어싱 제거 필 터의 내부 메모리에 의해 발생하는 양자화 오류
이다. 또한, $N_{Q}^{M C D}=N_{Q_{2}}^{A P F}+N_{Q_{3}}^{A P F}+N_{Q_{2}}^{F F T}+N_{Q 3}^{F F T}$ 는 $\mathrm{MCD}$ 에서 발생하는 양자화 오류들의 합으로 $N_{Q_{2}}^{A P F}=N_{Q}^{2} /\left(1-a^{2}\right)$ 은 $\mathrm{MCD}$ 의 $\mathrm{APF}$ (All Pass Filter)에 의한 양자화 오류; $N_{Q_{3}}^{A P F}=N_{Q}^{2} /\left(1-a^{2}\right)$ 은 $\mathrm{APF}$ 의 수학적 연산에 의한 양자화 오류; $N_{Q 2}^{F F T}=3 \cdot 2^{-2 b} N / 4$ 은 FFT 알고리즘에 의해 발생 하는 양자화 오류; $N_{Q_{3}}^{F F T}=2\left(N \cdot \log _{2} N\right) N_{Q}^{2}$ 는 FFT 프로세서의 계수에 의한 양자화 오류이다. $N_{0}$ 는 $\mathrm{AWGN}$ 의 전력 스펙트럼 밀도; $\gamma$ 는 전송률 변환필터에 의해 발생하는 격감의 인수 값; $S$ 는 수신단에서 입력되는 신호의 전력; $S_{k}$ 는 $k$ 번째 채널 신호의 전력; $a$ 는 $\mathrm{APF}$ 의 계수이다. $N_{Q}^{2}=2^{-2 b} / 3$ 는 디지털 변환기에서 발생하는 양 자화 오류; $b=\log _{2} M$ 는 양자화 비트 값; $\omega_{k}=2 \pi f_{k}$ 는 $k$ 번째 신호의 반송파 주파수; $f_{k}$ 는 $k$ 번째 채널의 중심 주파수이다. $P$ 와 $Q$ 는 전송 률 변환 필터에서 신호의 샘플링 주파수를 조 정함으로써 $R_{\text {signal }}$ 의 변환 비를 설정하는 파라 미터이며, $B_{k}$ 는 각 채널의 대역폭, $E_{k}$ 는 $k$ 번째 채널 신호의 심볼 에너지, $N$ 은 채널의 수, $C$ 는 디지털 앨리어싱 제거 필터의 탭 수, $T$ 는 수 신 신호의 심볼 주기이다[4].

양자화 오류는 전처리 과정의 디지털 변환기 에서 발생하며 신호 샘플의 값과 가장 근접한 양 자화 비트 값으로 변환시키기 때문에 양자화 레 벨이 클수록 양자화 비트 수는 증가하지만 신호 샘플의 값과 양자화 비트 값의 차이를 줄일 수 있어 양자화 오류를 줄일 수 있다. 또한 양자화 오류는 이후에 존재하는 필터들과 $\mathrm{FFT}$ 프로세서 의 디지털 신호처리 과정을 거치면서 신호의 $\mathrm{SNR}$ 에 미치는 영향이 증가하는 것을 식(3)을 통 해 확인할 수 있다. 양자화 레벨 $M$ 이 증가할수 록 디지털 변환기에서 발생하는 양자화 오류 $N_{Q}^{2}$ 이 작아지게 되며, $N_{Q}^{2}$ 의 감소는 전체 양자화 오류의 감소로 이어져 신호의 SNR에 미치는 영 향도 줄어들게 된다. 그러나 $M$ 을 증가시키면 신 호의 $R_{\text {signal }}$ 이 증가하지만, $R_{\text {signal }}$ 은 $\mathrm{MCDD}$ 의 $R_{\text {system }}$ 을 초과할 수 없으므로 $M$ 값을 크게 설정 하는데 한계가 있다.

$$
S N R_{k}=\frac{E_{k} \int_{\frac{(k-1) \pi P}{Q}}^{\frac{k \pi P}{Q}} \sin c^{2}\left[\frac{P\left(\omega-\omega_{k}\right)}{4 N Q \pi T}\right] d \omega}{\frac{P N_{0} \pi}{4 Q}+8 Q T N\left[\frac{N_{Q}^{A}+S_{k} \gamma^{2} N+N(1-a)\left(N_{Q}^{M C D}+S_{k} \gamma^{2} Q\right)}{Q N(1-a)}\right] \frac{\pi P}{Q}}
$$




\section{2 보호 대역에 의한 영향 분석}

주파수 오프셋은 지상국의 주파수 상향 변환 기나 $\mathrm{MCDD}$ 의 주파수 하향 변환기의 오작동 또 는 도플러 천이(Doppler Shift)에 의해서 발생하 며, $\mathrm{MCDD}$ 의 신호 분리 과정에서 채널 간 간섭 과 유사한 영향을 끼쳐 $\mathrm{OBP}$ 위성 시스템의 $\mathrm{BER}$ 성능을 열화시킨다. 이러한 성능 열화를 줄이기 위해 각 채널 사이에 신호를 보호하기 위한 보 호 대역을 삽입한다. 수신 신호의 각 채널당 대 역폭이 동일하다고 가정하면 $B_{1}=B_{2}=\cdots=B_{N}$ 이 되므로 $N$ 개의 채널을 갖는 수신 신호의 대역 폭 $B_{\text {signal }}=N B_{k}$ 가 된다. 이 때, 주파수 오프셋에 의한 영향을 줄이기 위해 각 채널 사이에 $B_{k}$ 의 $\alpha$ 배에 해당하는 보호 대역을 삽입하면 각 채널 의 대역폭은 $(1+\alpha) B_{k}$ 가 되며 수신 신호의 대역 폭 $B_{\text {signal }}$ 은 다음과 같다.

$$
B_{\text {signal }}=(1+\alpha) N B_{k}[H z]
$$

채널 사이에 보호 대역이 존재하면 한 채널 신호의 대역폭은 $B_{k}$ 가 되지만 $\mathrm{MCDD}$ 에서 채널 의 대역폭은 $(1+\alpha) B_{k}$ 가 되므로 $\alpha$ 보다 작은 주파수 오프셋이 발생하는 경우에는 $(1+\alpha) B_{k}$ 의 채널 대역폭 내부에 수신 신호가 모두 존재 하게 되므로 주파수 오프셋의 영향을 받지 않 고 신호를 분리할 수 있다. 또한, $\alpha$ 보다 큰 주 파수 오프셋이 발생하는 경우에도 $\mathrm{MCDD}$ 의 채 널 대역폭이 $\alpha$ 만큼 넓어졌기 때문에 주파수 오 프셋의 영향을 보호 대역의 넓이만큼 줄일 수 있다[4].

주파수 오프셋이 발생하는 경우, $\alpha$ 의 보호 대역이 삽입된 $k$ 번째 채널 신호의 $\mathrm{SNR}$ 은 식(5) 와 같이 표현될 수 있으며 여기서 $\omega_{d}=2 \pi f_{d}$ 는 주파수 오프셋에 의한 영향이고, $f_{d}=\triangle f / B_{k}$ 로 주파수 오프셋 $\triangle f$ 를 $B_{k}$ 의 비율로 표현한 것이 다[4].

주파수 오프셋의 영향 $\omega_{d}$ 는 $\mathrm{MCD}$ 에서 $k$ 번째 채널을 정확히 분리하지 못하게 만들기 때문에 신호의 SNR에 채널 간 간섭과 유사한 영향을 끼 치는 것을 식(5)를 통해 알 수 있으며, $\alpha$ 의 보호
대역이 삽입되면 주파수 오프셋의 영향을 $2 \pi \alpha B_{k}$ 만큼 줄일 수 있는 것을 알 수 있다. 그러므로 $\alpha$ 가 증가할수록 주파수 오프셋의 영향을 많이 줄 일 수 있기 때문에 $\alpha$ 값을 크게 설정하는 것이 유리하다. 그러나 가용 주파수 대역의 제한 및 $\alpha, B_{\text {signal }}$ 그리고 $R_{\text {signal }}$ 간의 관계를 고려하면 $\alpha$ 값을 크게 설정하는데 한계가 있다.

\section{3 보호 대역과 양자화 레벨을 고려한 성능 분석}

수신된 다채널 신호는 $\mathrm{MCDD}$ 에 의해 분리되 기 전에 디지털 변환기를 통과하여 디지털 신호 로 변환되어야 한다. 보호 대역이 삽입된 다채널 신호의 비트 전송률 $R_{\text {signal }}$ 은 식(1)과 식(4)를 이 용하여 다음과 같이 나타낼 수 있다.

$$
R_{\text {signal }}=2 \beta(1+\alpha) N B_{k} \log _{2} M[b p s]
$$

$\mathrm{MCDD}$ 를 이용하여 채널을 분리할 때, $\mathrm{MCDD}$ 프로세서의 데이터 전송률 $R_{\text {signal }}$ 이 무한하다고 가정하면, 양자화 레벨 $M$ 을 크게 하여 양자화 오류의 영향을 줄일 수 있고 무한히 넓은 보호 대역도 삽입할 수 있다. 그러나 데이터 전송률 $R_{\text {system }}$ 이 무한한 시스템은 존재할 수 없기 때문 에 실제 시스템에서는 $R_{\text {system }} \geq R_{\text {signal }}$ 을 만족 해야 하고 $R_{\text {signal }}$ 에 영향을 미치는 양자화 레벨 $M$ 과 보호 대역의 넓이 $\alpha$ 는 다음과 같은 조건을 만족해야 한다.

$$
R_{\text {system }} \geq 2 \beta(1+\alpha) N B_{\text {signal }} \log _{2} M[b p s]
$$

이 때, 시스템을 최대한 효율적으로 사용하기 위해 $R_{\text {system }}=R_{\text {signal }}$ 이 되도록 설계하는 것이 좋 으며, 양자화 레벨 $M$ 은 항상 2 이상인 양수이어 야 하므로 식(7)로부터 주파수 오프셋의 영향을 줄이기 위해 삽입할 수 있는 최대 보호 대역의 비 $\alpha_{M A X}$ 를 다음과 같이 얻을 수 있다.

$$
\alpha_{M A X}=\frac{R_{\text {system }}}{2 \beta N B_{k} \log _{2} M}-1
$$

여기서 양자화 레벨 $M$ 이 커질수록 채널 사이에 삽입 가능한 최대 보호 대역 $\alpha_{M A X}$ 는 좁아지고,

$$
S N R_{k}=\frac{E_{k} \int_{\frac{(k-1) \pi P}{Q}}^{\frac{k \pi P}{Q}} \sin c^{2}\left[\frac{P\left(\omega-\omega_{k}+2 \pi \alpha B_{k}-\omega_{d}\right)}{4 N Q \pi T}\right] d \omega}{\frac{P N_{0} \pi}{4 Q}+\sum_{\substack{p=1 \\ p \neq k}}^{N} E_{p} \int_{\frac{k \pi-1) \pi P}{Q}}^{\frac{k \pi P}{Q}} \sin c^{2}\left[\frac{P\left(\omega-\omega_{p}+2 \pi \alpha B_{k}-\omega_{d}\right)}{4 N Q \pi T}\right] d \omega}
$$


양자화 레벨 $M$ 이 작아질수록 채널 사이에 삽입 가능한 최대 보호 대역 $\alpha_{M A X}$ 가 넓어짐을 확인 할 수 있다.

주파수 오프셋과 양자화 오류는 발생 원인이 서로 다르기 때문에 보호 대역과 양자화 레벨간 의 관계를 고려하지 않은 $k$ 번째 채널 신호의 $\mathrm{SNR}$ 을 식(9)와 같이 표현하였다[4]. 그러나 실제 시스템은 한정된 데이터 전송률을 갖기 때문에 $R_{\text {system }}$ 이 제한된 상황에서는 수신된 다채널 신 호의 비트 전송률 $R_{\text {signal }}$ 이 $R_{\text {system }}$ 을 초과할 수 없으므로 보호 대역과 양자화 레벨간의 관계를 고려한 $k$ 번째 채널 신호의 SNR은 식(10)과 같이 표현된다.

시스템의 데이터 전송률이 제한되지 않은 경 우, 주파수 오프셋의 영향 $\omega_{d}$ 는 보호 대역의 비 $\alpha$ 에 의해 $2 \pi \alpha B_{k}$ 만큼 줄어든다. 그러나 시스템 의 데이터 전송률이 제한된 경우, 주파수 오프셋 의 영향 $\omega_{d}$ 는 $2 \pi \alpha_{M A X} B_{k}$ 만큼 줄어들게 되고 $\alpha_{M A X}$ 는 양자화 레벨 $M$ 에 의해서 변하게 되므로 보호 대역과 양자화 레벨이 상호 관계를 가짐을 확인 할 수 있다.

$\mathrm{MCDD}$ 를 이용한 멀티미디어 데이터 전송 시 보호 대역과 양자화 레벨간의 상호 관계를 고 려한 BER 성능을 분석하기 위하여 DVB-S 시스 템을 고려한다. MCDD 모델로는 현재 DVB-S 서비스에 사용되고 있는 HOT BIRD 6 Satellite 의 $\mathrm{MCDD}$ 를 사용한다고 가정한다[5]. 각각의 파라미터들과 그 값들을 정리하여 Table 1에 나타내었다[4]-[6]. 6개의 채널에 $5.2 \mathrm{MHz}$ 의 대 역폭을 갖는 신호가 전송된다면 $\mathrm{MCDD}$ 에서 2048의 양자화 레벨 즉, 11비트 이상으로 양자 화를 하면 보호 대역을 삽입하지 않아도 수신 신호의 비트 전송률 $R_{\text {signal }}$ 이 $915 \mathrm{Mbps}$ 이상이 되어 $R_{\text {system }}$ 을 초과하기 때문에 왜곡 없는 채 널 분리가 불가능하다. 그러므로 주어진 조건에 서 1024의 양자화 레벨, 즉, 10 비트 이하로 양
Table 1. Simulation Parameters

\begin{tabular}{|c|c|}
\hline Parameter & Value \\
\hline 변조방식 & QPSK \\
\hline$R_{\text {system }}$ & $880 \mathrm{Mbps}$ \\
\hline$B_{k}$ & $5.2 \mathrm{MHz}$ \\
\hline$\beta$ & $4 / 3$ \\
\hline$N$ & 6 \\
\hline$a$ & 0.99 \\
\hline$\gamma$ & 1.0258 \\
\hline$C$ & 9 \\
\hline$P$ & 4 \\
\hline$Q$ & 3 \\
\hline
\end{tabular}

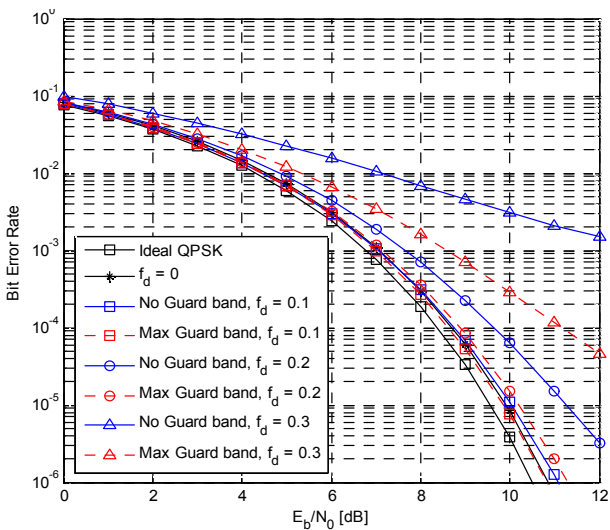

Fig. 2. BER performance for 10 bits quantization

자화를 해야 한다. 10 비트로 양자화를 하는 경 우 주파수 오프셋과 보호 대역의 삽입 여부에 따른 BER 성능을 Fig. 2에 나타내었다.

10 비트로 양자화를 하는 경우, 주파수 오프셋 이 발생하지 않으면 약 $10 \mathrm{~dB}$ 에서 $10^{-5}$ 의 $\mathrm{BER}$

$$
\begin{gathered}
S N R_{k}=\frac{E_{k} \int_{\frac{(k-1) \pi P}{Q}}^{\frac{k \pi P}{Q}} \sin c^{2}\left[\frac{P\left\{\omega-\omega_{k}+2 \pi \alpha B_{k}-\omega_{d}\right\}}{4 N Q \pi T}\right] d \omega}{\frac{P N_{0} \pi}{4 Q}+\sum_{\substack{p=1 \\
p \neq k}}^{N} E_{p} \int_{\frac{k \pi-1) \pi P}{Q}}^{\frac{k \pi P}{Q}} \sin c^{2}\left[\frac{P\left\{\omega-\omega_{p}+2 \pi \alpha B_{k}-\omega_{d}\right\}}{4 N Q \pi T}\right] d \omega+8 Q T N\left[\frac{N_{Q}^{A}+S_{k} \gamma^{2} N+N(1-a)\left(N_{Q}^{M C D}+S_{k} \gamma^{2} Q\right)}{Q N(1-a)}\right] \frac{\pi P}{Q}} \\
S N R_{k}=\frac{E_{k} \int_{\frac{(k-1) \pi P}{Q}}^{\frac{k \pi P}{Q}} \sin c^{2}\left[\frac{P\left\{\omega-\omega_{k}+2 \pi \alpha_{M A X} B_{k}-\omega_{d}\right\}}{4 N Q \pi T}\right] d \omega}{\frac{P N_{0} \pi}{4 Q}+\sum_{\substack{p=1 \\
p \neq k}}^{N} E_{p} \int_{\frac{(k-1) \pi P}{Q}}^{\frac{k \pi P}{Q}} \sin c^{2}\left[\frac{P\left\{\omega-\omega_{p}+2 \pi \alpha_{M A X} B_{k}-\omega_{d}\right\}}{4 N Q \pi T}\right] d \omega+8 Q T N\left[\frac{N_{Q}^{A}+S_{k} \gamma^{2} N+N(1-a)\left(N_{Q}^{M C D}+S_{k} \gamma^{2} Q\right)}{Q N(1-a)}\right] \frac{\pi P}{Q}}
\end{gathered}
$$


성능을 얻을 수 있다. 이는 양자화 오류가 없는 경우 QPSK 신호가 $9.6 \mathrm{~dB}$ 에서 $10^{-5}$ 의 $\mathrm{BER}$ 성능 을 갖는 것과 비교해보면, 양자화 오류의 영향이 약 $0.4 \mathrm{~dB}$ 의 성능 열화를 일으킨다는 것을 확인할 수 있다. 또한, 주파수 오프셋의 영향이 커질수록 $\mathrm{BER}$ 성능 열화도 커짐을 확인할 수 있다. 그러 나 채널 사이에 식(8)을 통해 얻을 수 있는 최대 의 보호 대역 $\alpha_{M A X}$ 를 삽입하면 주파수 오프셋의 영향을 약 0.06정도 줄일 수 있다. $f_{d}=0.1$ 인 경 우에는 보호 대역에 의해 주파수 오프셋의 영향 이 줄어들어 주파수 오프셋에 의한 성능 열화가 거의 나타나지 않는 것을 볼 수 있으며, $f_{d} \geq 0.2$ 인 경우에는 주파수 오프셋의 영향으로 인한 성능 열화가 발생하지만 주파수 오프셋의 영향이 줄어들어 $\mathrm{BER}$ 성능이 개선됨을 확인할 수 있다.

Fig. 3에는 주파수 오프셋의 영향을 줄이기 위 한 보호 대역을 최대한으로 삽입한 경우 양자화 비트 수에 따른 BER 성능을 나타내었다.

Fig. 3에서, 주파수 오프셋이 발생하지 않는 경 우의 BER 성능과 $f_{d}=0.1$ 의 주파수 오프셋이 발 생하는 경우의 BER 성능이 거의 동일한 것을 볼 수 있으며, 이는 주파수 오프셋에 의한 영향이 보호 대역에 의해 제거되었음을 알 수 있다. 또 한, 양자화 레벨 $M$ 이 클수록 더 좋은 $\mathrm{BER}$ 성능 을 갖는 것을 확인할 수 있다. 그러나 $f_{d} \geq 0.3$ 인 경우에는 9비트로 양자화를 하고 넓은 대역폭을 삽입하여 주파수 오프셋의 영향을 많이 줄이는 것이 10 비트로 양자화를 하여 양자화 오류를 줄 이는 것 보다 더 좋은 $\mathrm{BER}$ 성능을 갖는 것을 확 인할 수 있다. 따라서, 일반적으로 $M$ 이 클수록

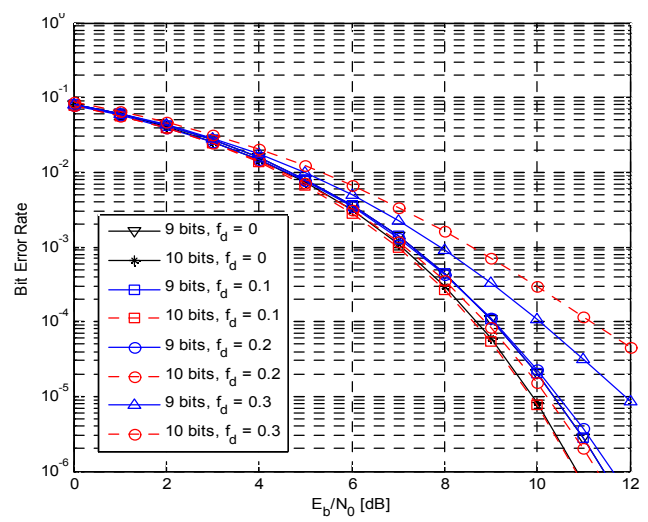

Fig. 3. BER performance with $\alpha_{\text {MAX }}$

$$
(b=9, \quad b=10)
$$

더 좋은 $\mathrm{BER}$ 성능을 갖지만 주파수 오프셋이 발 생하는 정도에 따라 양자화 레벨 $M$ 을 줄이고 넓은 보호 대역을 삽입하는 것이 더 좋은 $\mathrm{BER}$ 성능을 가질 수 있음을 확인 할 수 있다. 그러므 로 시스템의 데이터 전송률 $R_{\text {system }}$ 이 제한된 환 경에서 주파수 오프셋에 따라 양자화 레벨 조정 을 통해 넓은 보호 대역을 삽입하여 $\mathrm{BER}$ 성능을 향상시킬 수 있다.

\section{III. 결 론}

$\mathrm{OBP}$ 위성 시스템의 $\mathrm{BER}$ 성능은 $\mathrm{MCDD}$ 의 신 호 분리 과정에서 주파수 오프셋 및 양자화 오류 등에 의해 발생하는 성능 열화의 영향을 받는다. 이러한 성능 열화를 줄이기 위한 방법으로는 채 널 사이에 보호 대역을 삽입하여 주파수 오프셋 의 영향을 줄이는 방법과 양자화 레벨을 조정하 여 양자화 오류는 줄이는 방법 등이 있다.

이 논문에서는 시스템 데이터 전송률이 제 한된 상황에서 보호 대역과 양자화 레벨간의 상호 관계를 살펴보고 이를 DVB-S 시스템에 적용하여 $\mathrm{BER}$ 성능을 분석하였다. $\mathrm{BER}$ 성능 의 분석을 통해 주파수 오프셋이 심할수록 양 자화 레벨을 줄이고 넓은 보호 대역을 삽입하 는 것이 더 좋은 $\mathrm{BER}$ 성능을 가질 수 있음을 확인하였다. 이 논문의 결과는 앞으로 $\mathrm{MCDD}$ 가 탑재된 $\mathrm{OBP}$ 위성 시스템 설계 시 주파수 오프셋에 따라 양자화 레벨 및 보호 대역 설정 에 유리한 자료로 활용될 수 있을 것으로 기대 된다.

\section{후 기}

본 연구는 한국연구재단을 통해 교육과학기술 부의 우주기초원천기술개발 사업(NSL, National Space Lab)으로부터 지원받아 수행되었습니다 (2010-0015083).

\section{참고문헌}

1) S. J. Lee, S. W. Lee, K. W. Kim, and J. S. Seo, "Personal and Mobile Satellite DMB Service in Korea", IEEE Trans. Broadcasting, vol. 53, no. 1, March 2007, pp. 179-197.

2) S. Scalise, R. Mura, and V. Mignone, "Air Interfaces for Satellite Based Digital TV Broadcasting in the Railway Environment", 
IEEE Trans. Broadcasting, vol. 52, no. 2, June 2006, pp. 158-166.

3) B. G. Evans, F. P. Coakly, M. H. M. E1-Amin, S. C. Lu, and C. W. Wong, "Baseband Switches and Transmultiplexers for Use in and On-Board Processing Mobile/Business Satellite System", IEE Proc. Communications, Radar, and Signal Processing, vol. 133, no. 4, July 1986, pp. 356-363.

4) J. Li, and J. H. Kim, "Performance Analysis of MF-TDMA Multi-Carrier
Demultiplexer/Demodulators(MCDDs) in the Presence of Critical Degrading Factors", IEEE Trans. Braodcasting, vol. 54, no. 3, September 2008, pp. 371-382.

5) A. Del Re, M. Re and G. C. Cardarilli, "Efficient Implementation of a Demultiplexer Based on a Multirate Filter Bank for the Skyplex Satellite DVB System", VLBI Design Journal, Taylor \& Francis Ltd, vol. 15, 2002, pp. 427-440.

6) Eutelsat, "Technical Guide - Overview of DVB", June 1999. 